Marquette University

e-Publications@Marquette

School of Dentistry Faculty Research and

Publications

Dentistry, School of

1-1-2009

\title{
Comparison of Porcelain Surface and Flexural Strength Obtained by Microwave and Conventional Oven Glazing
}

Soni Prasad

Marquette University, soni.prasad@marquette.edu

Edward A. Monaco, Jr.

State University of New York at Buffalo

Hyeongil Kim

State University of New York at Buffalo

Elaine L. Davis

State University of New York at Buffalo

Jane D. Brewer

State University of New York at Buffalo

Accepted version. The Journal of Prosthetic Dentistry, Vol. 101, No. 1 (January 2009): 20-28. DOI. (C) 2009 Elsevier B.V. Used with permission.

Soni Prasad was affiliated with State University of New York at Buffalo at the time of publication. 
Marquette University

e-Publications@Marquette

\section{Dentistry Faculty Research and Publications/School of Dentistry}

This paper is NOT THE PUBLISHED VERSION; but the author's final, peer-reviewed manuscript. The published version may be accessed by following the link in the citation below.

The Journal of Prosthetic Dentistry, Vol. 101, No. 1 (January, 2009): 20-28. DOI. This article is @ Elsevier and permission has been granted for this version to appear in e-Publications@Marquette. Elsevier does not grant permission for this article to be further copied/distributed or hosted elsewhere without the express permission from Elsevier.

\section{Comparison of Porcelain Surface and Flexural Strength Obtained by Microwave and Conventional Oven Glazing}

Soni Prasad

School of Dental Medicine, State University of New York at Buffalo, Buffalo, NY

Edward A. Monaco

Department of Restorative Dentistry, School of Dental Medicine, State University of New York at Buffalo, Buffalo, NY

Hyeongil Kim

Department of Restorative Dentistry School of Dental Medicine, State University of New York at Buffalo, Buffalo, NY

Elaine L. Davis

Department of Oral Diagnostic Sciences. School of Dental Medicine, State University of New York at Buffalo, Buffalo, NY

Jane D. Brewer

Department of Restorative Dentistry. School of Dental Medicine, State University of New York at Buffalo, Buffalo, NY 


\section{Statement of problem}

Although the superior qualities of microwave technology are common knowledge in the industry, effects of microwave glazing of dental ceramics have not been investigated.

\section{Purpose}

The purpose of this study was to investigate the surface roughness and flexural strength achieved by glazing porcelain specimens in a conventional and microwave oven.

\section{Material and methods}

Thirty specimens of each type of porcelain (Omega 900 and IPS d.Sign) were fabricated and sintered in a conventional oven. The specimens were further divided into 3 groups $(n=10)$ : hand polished (using diamond rotary ceramic polishers), microwave glazed, and conventional oven glazed. Each specimen was evaluated for surface roughness using a profilometer. The flexural strength of each specimen was measured using a universal testing machine. A 2-way ANOVA and Tukey HSD post hoc analysis were used to determine significant intergroup differences in surface roughness $(\alpha=.05)$. Flexural strength results were also analyzed using 2-way ANOVA, and the Weibull modulus was determined for each of the 6 groups. The surfaces of the specimens were subjectively evaluated for cracks and porosities using a scanning electron microscope (SEM).

\section{Results}

A significant difference in surface roughness was found among the surface treatments $(P=.02)$. Followup tests showed a significant difference in surface roughness between oven-glazed and microwaveglazed treatments $(P=.02)$. There was a significant difference in flexural strength between the 2 porcelains $(P<.005)$, but no significant difference in flexural strength by surface treatment $(P=.48)$. The Weibull modulus value for the Omega 900 microwave-glazed group was the highest (1.9) as compared to the other groups.

\section{Conclusions}

The surface character of microwave-glazed porcelain was superior to oven-glazed porcelain. Omega 900 had an overall higher flexural strength than IPS d.Sign. Weibull distributions of flexural strengths for Omega 900 oven-glazed and microwave-glazed specimens were similar. SEM analysis demonstrated a greater number of surface voids and imperfections in IPS d. Sign as compared to Omega 900. (J Prosthet Dent 2009;101:20-28)

\section{Clinical Implications}

The effect of microwave glazing on the properties of dental ceramic is not known. The present investigation indicates that microwave glazing results in superior surface properties as compared to conventional oven glazing for the 2 ceramics evaluated. 
Glazing, by definition, refers to the final firing of porcelain in which the surface is vitrified and a high gloss is imparted to the material. 1 During this procedure, the surface of the porcelain melts and fuses to fill in small surface irregularities, thereby providing the restoration with a smooth, glossy finish. Some authors advocate glazing ceramics after polishing for a superior surface and strength. $\frac{3,4,}{5}$ Monasky et al $\underline{3}$ found that a glazed ceramic surface increased flexural strength and reduced surface roughness. Early researchers determined that glazing was necessary after porcelain adjustment in the clinical setting. ${ }^{4} \underline{5}$ Glazing also allows for easy removal of plaque from the porcelain surface. $\underline{6}, \underline{z}$

A few studies report that surface roughness affects the strength of dental ceramics. $\underline{8}, \underline{9}, \underline{10}$ The presence of voids and porosities has been shown to not only increase surface roughness, but to decrease strength of porcelains. $\underline{11}$ Glazing is believed to increase the strength of ceramic materials by reducing the depth and/or sharpness of the critical flaws. $\underline{12}$ In contrast to these studies, Morgano et al, $\underline{13}$ in a study of strengthening effects on ceramics, concluded that glazing did not change the flexural strength of dental porcelains and that polishing alone was adequate. Fairhurst et al, $\underline{14}$ in a study of the effect of glazing on porcelain strength, also concluded that glazing did not improve the strength of specimens. To date, there are no conclusive studies to validate that either glazing or polishing impart superior characteristics to dental ceramic.

According to Kelly et al, $\underline{\underline{15}}$ the origin of fracture in the porcelain is probably due to the presence of an increased number and location of porosities. Therefore, the control of porosity is important for achieving acceptable flexural strength. The process of polishing to eliminate defects and flaws from the treated surface has also been correlated with higher strength. $\underline{12}$

The bulk of porosity reduction occurs in the sintering process. $\underline{11}$ Che-ung and Darvell $\underline{11}$ concluded that a minimum number of porosities can be achieved when high sintering temperatures are attained quickly. Therefore, to obtain minimum porosity, the porcelain specimen must be heated uniformly in the shortest time possible. This supports the contention for the use of microwave energy to sinter ceramics, as higher temperatures can be reached in a short time.

Use of a standard dental conduction oven for sintering dental ceramic is not a uniform heating process. Heat is applied to the surface of the ceramic and reaches the core by thermal conduction. This results in the production of high temperature gradients and stress within the ceramic material. High sintering temperatures achieve greater densification, but high temperature also results in an increase in

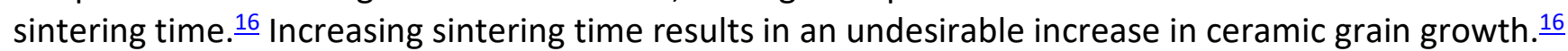
These factors potentially produce an inferior product with higher failure rates. $\underline{16}$

The possibility of processing industrial ceramic materials with microwave energy was first explored in the 1950s and investigated by Tinga et al $\underline{17}$ in the 1960s. Microwave sintering has several benefits over conventional sintering, including more precise and controlled volumetric heating, faster ramp-up temperature, lower energy consumption, and improved properties of the ceramic materials. $\underline{18}$ The primary reason the microwave process yields better mechanical properties is due to the fine grain size produced. The shapes of the porosities, if present, are different from those generated during conventional heating. In microwave-processed specimens, round-edged porosities were observed, which produced higher toughness. $\underline{\underline{19}}$ Berteaud and Badot $\underline{20}$ were the first to report achieving high 
ceramic densification rates with microwave energy. There is evidence that significant enhancements in sintering results can be achieved by microwave sintering. $\underline{16}, \underline{19}, \underline{20}, \underline{21}$

The nature of the interaction between microwaves and ceramics is complex and is dependent on the dielectric property of the ceramic. The dielectric property of a material is its ability to continuously hold electrons at a high voltage. A material with good dielectric properties supports an electric field with virtually no current passing through it. $\underline{22}$ Ceramics are said to have excellent dielectric properties. When microwaves penetrate the ceramic material, microwave energy is propagated due to the generation of an internal electric field. $\underline{21}$ This induces the translation motion of free and bound electrons. Due to the superior dielectric property of ceramics, the translation motion of the electrons is resisted, thereby causing loss and attenuation of the electric field. This loss results in the production of heat, leading to volumetric heating of the ceramic specimen. $\underline{\underline{21}}$

Microwave sintering is fundamentally different from conventional oven sintering. In conventional firing, heat is applied to the surface of the ceramic and reaches the core by thermal conduction, producing high temperature gradients and stress. In microwave processing, the ceramic is heated both internally and externally. $\underline{\underline{21}}$ In addition to the heat generated within the material, susceptors made of silicon carbide or molybdenum silicate are placed around the ceramic to heat the specimen externally by thermal conduction (Fig. 1). As a result of this internal and external volumetric heating, the thermal gradient and flow of heat in the ceramic body is evenly applied. This makes it possible to heat small and large specimens uniformly and rapidly, with less thermal stress. $\underline{21}$

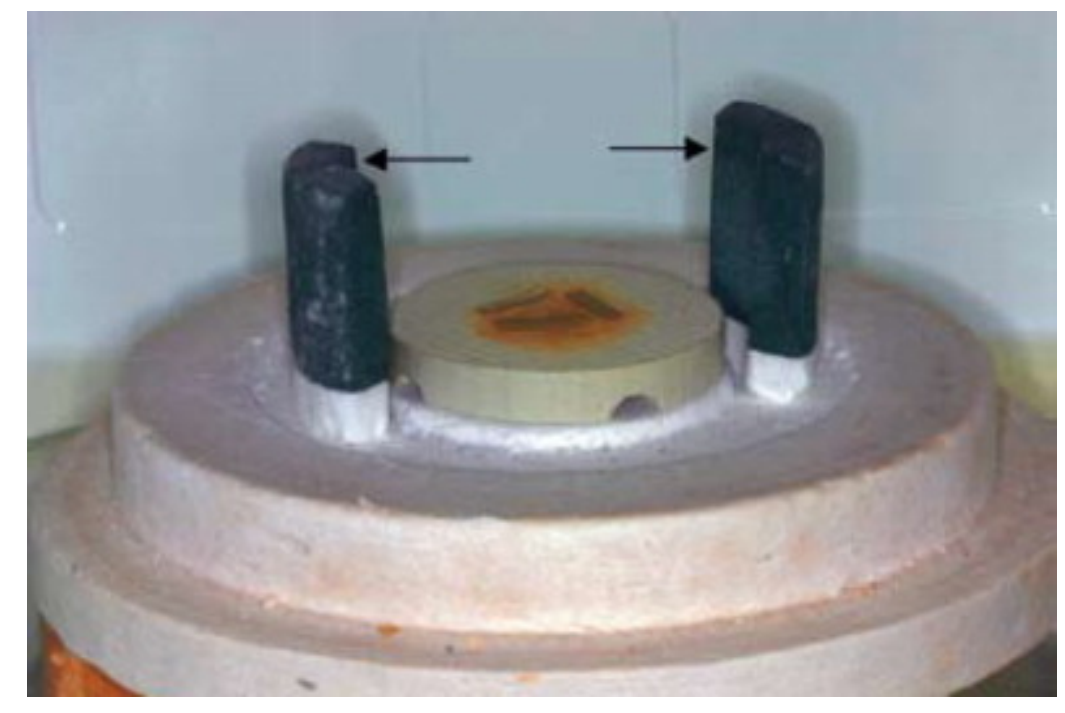

1. SiC susceptors in position inside microwave.

Many ceramic materials do not absorb microwaves well at room temperature. Susceptors (Fig. 1) help increase the temperature until the dielectric loss in the ceramic is high enough that the ceramic couples directly with the microwave field. $\underline{\underline{19}}$ For example, using silicon carbide susceptors, zirconia will heat, primarily by radiation from the silicon carbide, until it reaches approximately $600^{\circ} \mathrm{C}$, whereby the zirconia couples preferentially and heats volumetrically. $\underline{\underline{19}}$ 
The advantage of improved mechanical properties through microwave sintering is primarily based on uniform volumetric heating and extremely rapid heat-up rates. $\frac{16}{6}$ Uniform heating results in a more uniform crystalline structure. In addition, uniform volumetric heating minimizes thermal heat-up stresses and allows for the sintering of larger and/or more complex green shapes. $\underline{16}$ Harmer and Brook $\underline{23}$ reported that rapid sintering produces a finer grain microstructure. By heating a specimen quickly to the high temperature, grain growth, a dominant process at low temperatures, is minimized. $\underline{23}$

There are several studies that have confirmed that microwave sintering is capable of producing ceramics which are superior when compared to those produced with conventional sintering. $\underline{16}, \underline{17}, \underline{18}, \underline{19}$, $\underline{20}, \underline{21}$ However, there are no studies that have investigated microwave glazing. The effect of microwave glazing on the properties of dental porcelain is unknown. Therefore, the purpose of this study was to investigate whether microwave-glazed specimens will produce smoother surfaces and higher flexural strength compared with hand-polished and conventional oven-glazed specimens. The null hypotheses were that: (1) there would be no difference in surface roughness among the 3 treatment groups of porcelain and among the porcelains themselves; and (2) there would be no difference in the flexural strength among the 3 treatment groups and among the porcelains evaluated.

\section{Material and methods}

Two commercial dental porcelains were used, Omega 900 (VITA Zahnfabrik, Bad Säckingen, Germany) and IPS d.Sign (Ivoclar Vivadent, Amherst, NY). A randomized control study was designed. Thirty specimens of IPS $d$.Sign and 30 of Omega 900 porcelain were fabricated in accordance with ADA Specification Number 69 for dental ceramics. $\stackrel{24}{ }$ A brass mold, $25 \mathrm{~mm} \times 5 \mathrm{~mm} \times 2 \mathrm{~mm}$, was used to fabricate the specimens. The porcelains were mixed with sculpting liquid and placed into the mold. Excess moisture was absorbed with a tissue (Kleenex; Kimberly-Clark, Neenah, Wis) and the porcelains were vibrated to remove porosities using an ultrasonic ceramic condenser (Ceramosonic; Unitek, Monrovia, Calif). To achieve ceramic specimens of superior quality, the specimens were placed in a heat-pressure condensation machine (Ivomat IP3; Ivoclar Vivadent) for drying under pressure. Heatpressure condensation is known to result in considerable reduction in porosity, shrinkage, and distortion in the porcelain. $\frac{25}{}$ All 60 specimens were then placed on a saggar tray (Honeycomb Mesh Saggar Tray; American Dental Supply, Allentown, Pa) and sintered in a conventional oven (Programat P200; Ivoclar Vivadent). Due to the small dimensions of the specimens, a single firing cycle for each specimen was adequate to achieve sintering. The heat-pressure condensation technique resulted in highly condensed ceramic particle specimens with minimal warping. The specimens were allowed to cool and then were finished with a laboratory diamond rotary cutting instrument (Flat-end taper laboratory diamond \#847; Brasseler USA, Savannah, Ga) and hand polished using laboratory diamond ceramic polishers (CeramiPro Dialite; Brasseler USA) with a slow-speed handpiece (Star; StarDental, Lancaster, Pa) at 10,000 RPM for 5 minutes.

The 30 specimens for each type of porcelain were further divided arbitrarily into 3 groups ( $n=10$ for each group) based on the surface treatment; 1 control and 2 test groups. Since all of the procedures involved in the fabrication of the specimens were similar (namely, all 60 specimens were sintered in a 
conventional oven and hand polished), this study used the sham control principle to rule out any bias that could affect the results. Ten hand-polished specimens of each porcelain type on which no further treatment was performed formed the sham control group and were regarded as the baseline. Specimens that were glazed in a microwave and those that were glazed in a conventional oven formed the test groups.

A custom-built microwave oven (ThermWave1.3; Ceralink, Inc, Troy, NY) was used in this study to glaze the test group specimens. It incorporated a water jacket to cool the system and was connected to a circulating water supply. It allowed the temperature inside the microwave oven to be raised to a maximum of $1600^{\circ} \mathrm{C}$. A pyro-meter/thermocouple was inserted from the top of the oven to accurately read the temperature inside the oven. A controller box was attached to the microwave to ensure that any prescribed temperature inside the chamber was precisely reached. The microwave operated at a frequency of $2.45 \mathrm{GHz}$ with a power output capability of $1.25 \mathrm{~kW}$. Ten specimens of each type of porcelain were glazed in the microwave oven at the recommended glazing temperature according to the manufacturer's instructions. The temperature and heat rate were set and monitored using the controller box and the pyrometer. It took an average of 6 minutes to glaze each specimen in the microwave oven.

The remaining 10 specimens in the test group for each type of porcelain consisted of specimens that were glazed in a conventional oven (Programat P200; Ivoclar Vivadent) under vacuum, according to the manufacturer's instructions. To ensure that the same amount of energy was imparted to the specimen as compared to the microwave oven, the conventional oven was calibrated according the manufacturer's instructions prior to glazing. The glazing temperature for IPS d.Sign specimens was $870^{\circ} \mathrm{C}$, with a ramp rate of $80^{\circ} \mathrm{C} / \mathrm{min}$ and a holding time of 1 minute. The vacuum phase during the glazing of IPS d.Sign porcelain specimens began at $460^{\circ} \mathrm{C}$ and ended at $869^{\circ} \mathrm{C}$. The glazing temperature for Omega 900 specimens was $900^{\circ} \mathrm{C}$, with a ramp rate of $75^{\circ} \mathrm{C} / \mathrm{min}$ and a holding time of 1 minute. There was no vacuum phase during the glazing of the Omega 900 porcelain specimens, in accordance with the manufacturer's instructions.

To avoid any bias, the examiner who made the measurements was blinded to the glazing processes for the specimens. Surface roughness was evaluated quantitatively using a profilometer (Dektak; Veeco Instruments, Inc, Plainview, NY) with a stylus diameter of $12.5 \mu \mathrm{m}$ and a stylus load of $10 \mathrm{mg}$. The entire length of the specimens was scanned using the profilometer. The surface roughness, or Ra value (angstrom, $\AA$ ) of each specimen was directly obtained via the computer attached to the profilometer to eliminate intraoperator bias. Three readings were made for each specimen. The mean Ra value for each specimen was calculated from the average of the 3 profilometer readings. All specimens were then fractured to determine the flexural strength. The length, width, and height of each specimen were determined after polishing using an electronic digital caliper (DC150; Duratool, Tali City, Taiwan).

Specimens were then placed in a 3-point bending fixture which held the ceramic specimens on 2 supports, $20 \mathrm{~mm}$ apart. The specimens were oriented so that the width of the bar was perpendicular to the applied force. A 3-point bend test was performed using a universal testing machine (Instron Model 4411; Instron Corp, Norwood, Mass). A load cell capacity of $1 \mathrm{kN}$ was used. The load point was placed at the center of the specimens and the specimens were loaded to fracture at a speed of $1.0 \mathrm{~mm} / \mathrm{min}$. 
The flexural strength values (MPa) for the specimens were computed based on the individual measurements of each specimen by the computer attached directly to the universal testing machine, using the following formula:

$\mathrm{M}=3 \mathrm{~W} 1 / 2 \mathrm{bd} \mathrm{d}^{2}$

where $W$ is the load to fracture $(N), I$ is the length of test specimen (mm), b is the specimen width (mm), and $d$ is the specimen thickness $(\mathrm{mm}) . \underline{26}$

Two-way analyses of variance (ANOVA) were used to statistically determine differences in surface roughness and flexural strength by surface treatment and porcelain type $(\alpha=.05)$. Statistical software (SPSS 16.0; SPSS, Inc, Chicago, III) was used to perform the analysis. In addition to the 2-way ANOVA, the Weibull modulus $(\mathrm{m})$ value was calculated for the 6 treatment groups.

The specimen surfaces were also evaluated subjectively for cracks and porosities using a field emission scanning electron microscope (SEM) operated at 25 KV (Hitachi S-4000; Hitachi High Technologies America, Inc, Pleasanton, Calif). Five specimens were selected from each group and studied under the microscope. Specimens were carbon coated prior to SEM observation. Secondary electron images showing the surface topography of each specimen were made.

\section{Results}

Mean Ra values are presented in Table I. Two-way ANOVA (Table II) indicated a significant difference in the surface roughness based on the surface treatment $\left(F_{2,54}=3.98, P=.02\right)$. There was no significant effect for type of porcelain used $\left(F_{1,54}=2.46, P=.12\right)$ and no significant interaction between surface treatment and porcelain type $\left(F_{2,54}=1.11, P=.33\right)$. These results indicate that there was no significant difference in the surface roughness between the 2 types of porcelain and that the difference in roughness by surface treatment did not depend on the type of porcelain used.

Table I. Surface roughness $(\AA ̊)$ means (SD) $(n=10)$

Porcelain

Hand Polished

7513.8

(3534.9)

Omega 900

6594.0

(2726.7)

Average
7054.0

(3108.6)
Oven Glazed

8372.0

(2762.3)

8442.9

(3264.2)

8407.4

(2943.3)
Microwave Glazed

7199.3

(2182.8)

4680.6

(1750.0)

5940.0

(2318.8)
Average

7695.0

(2824.7)

6572.5

(3000.9)

7133.8

(2944.2) 
Table II. Two-way ANOVA results, surface roughness

\begin{tabular}{lclccc}
\multicolumn{1}{c}{ Source } & SS & $\boldsymbol{d f}$ & MS & $\boldsymbol{F}$ & $\boldsymbol{P}$ \\
Porcelain & $18,901,474$ & 1 & $18,901,474$ & 2.46 .12 \\
Surface treatment & $61,075,144$ & 2 & $30,537,572$ & 3.98 .02 \\
Porcelain $\times$ treatment & $17,074,111$ & 2 & $8,537,055$ & 1.11 .33 \\
Error & $414,385,538$ & 54 & $7,673,806$ & \\
Total & $3,564,877,160$ & 60
\end{tabular}

Follow-up Tukey multiple comparison tests (Table III) showed a significant difference in surface roughness between conventional oven-glazed and microwave-glazed specimens $(P=.02)$. The surfaces of oven-glazed specimens had greater roughness. However, there was no significant difference in the mean surface roughness between oven-glazed (8407.4 $\mathrm{A}$ ) and hand-polished specimens (7053.9 $\mathrm{A})$ or between microwave-glazed (5934.0 ̊) and hand-polished specimens (7053.9 ̊̊).

Table III. Tukey multiple comparison results for surface roughness by surface treatment

95\% Confidence Interval

\begin{tabular}{|c|c|c|c|c|c|}
\hline $\begin{array}{c}\text { Surface } \\
\text { Treatment }\end{array}$ & $\begin{array}{c}\text { Surface } \\
\text { Treatment }\end{array}$ & $\begin{array}{c}\text { Mean } \\
\text { Difference }\end{array}$ & Standard Error & $\begin{array}{l}\text { Upper } \\
\text { Bound }\end{array}$ & $\begin{array}{l}\text { Lower } \\
\text { Bound }\end{array}$ \\
\hline $\begin{array}{l}\text { Hand polished } \\
757.6\end{array}$ & Oven glazed & -1353.5 & 876.0 & $.28-3464.7$ & 757.6 \\
\hline $\begin{array}{l}\text { Hand polished } \\
3225.0\end{array}$ & Microwave glazed & 1113.9 & 876.0 & $.42-997.2$ & 3225.0 \\
\hline $\begin{array}{l}\text { Oven glazed } \\
4578.6\end{array}$ & Microwave glazed & $2467.5^{*}$ & 876.0 & .02356 .3 & 4578.6 \\
\hline
\end{tabular}

Mean flexural strength values are presented in Table IV. Two-way ANOVA (Table V) indicated a significant difference in flexural strength between the 2 porcelains $\left(F_{1,54}=25.47, P<.005\right)$. There was no significant effect for surface treatment $\left(F_{2,54}=0.74, P=.48\right)$ and no significant interaction between porcelain type and surface treatment $\left(F_{2,54}=2.27, P=.11\right)$. Examination of the means for the 2 porcelain types indicated that the mean flexural strength of IPS $d$.Sign porcelain was significantly lower than that of Omega 900 porcelain (59.7 and 82.6 MPa, respectively).

Table IV. Flexural strength (MPa) means (SD) ( $\mathrm{n}=10)$

Porcelain Hand Polished

IPS d.Sign 64.4

Omega 900
Microwave Glazed 51.2

86.5
86.0

\section{Average}

59.7

82.6 


\begin{tabular}{|c|c|c|c|c|c|c|}
\hline \multirow[t]{2}{*}{ Porcelain } & Hand Polished & Oven Glazed & \multicolumn{3}{|c|}{ Microwave Glazed } & \\
\hline & (19.4) & (19.1) & $(16.2)$ & & & (18.4) \\
\hline \multirow[t]{2}{*}{ Average } & 69.9 & 75.0 & 68.6 & & & 71.2 \\
\hline & $(18.0)$ & $(22.6)$ & $(23.1)$ & & & $(21.2)$ \\
\hline \multicolumn{7}{|c|}{ Table V. Two-way ANOVA results, flexural strength } \\
\hline & Source & SS & $d f$ & MS & $\mathbf{F}$ & $\boldsymbol{P}$ \\
\hline \multicolumn{2}{|l|}{ Porcelain } & 7879 & 1 & 7879 & 25.47 & $<.005$ \\
\hline \multicolumn{2}{|c|}{ Surface treatment } & 459 & 2 & 230 & 0.74 & .48 \\
\hline \multicolumn{2}{|c|}{ Porcelain $\times$ treatment } & 1404 & 2 & 702 & 2.27 & .11 \\
\hline \multicolumn{2}{|l|}{ Error } & 16,707 & 54 & 309 & & \\
\hline \multicolumn{2}{|l|}{ Total } & 330,300 & 60 & & & \\
\hline
\end{tabular}

The results of Weibull modulus values $(\mathrm{m})$ for each of the 6 groups are summarized in Table VI. Omega 900 specimens performed consistently better than IPS d.Sign specimens, with higher $\mathrm{m}$ values. The $\mathrm{m}$ value for the IPS d.Sign hand-polished group was 1.6; for the IPS d.Sign oven-glazed and microwaveglazed groups, m values were 1.2 and 1.6, respectively. The $\mathrm{m}$ value for Omega 900 hand-polished specimens was 1.3; for oven-glazed and microwave-glazed groups, m values were 1.7 and 1.9, respectively. Flexural strength performances for Omega 900 oven-glazed and Omega 900 microwaveglazed specimens were similar. These results indicate that microwave glazing can be a viable option for glazing porcelain specimens.

Table VI. Weibull modulus values, flexural strength

\section{Groups}

\section{Weibull Modulus (m)}

IPS d.Sign hand polished

1.6

IPS d.Sign oven glazed

1.2

IPS d.Sign microwave glazed

1.6

Omega 900 hand polished

Omega 900 oven glazed

Omega 900 microwave glazed

Specimens were assessed subjectively under a scanning electron microscope. The surface of microwave-glazed porcelain (IPS d.Sign, Fig. 2) (Omega 900, Fig. 3) showed fewer and smaller voids and appeared to be smoother when compared to the conventional oven-glazed porcelain (IPS d.Sign, Fig. 4) (Omega 900, Fig. 5). In addition, Omega 900 specimens (i․ 6) appeared to have fewer voids and surface irregularities when compared to IPS d.Sign specimens (Fig. 7). 


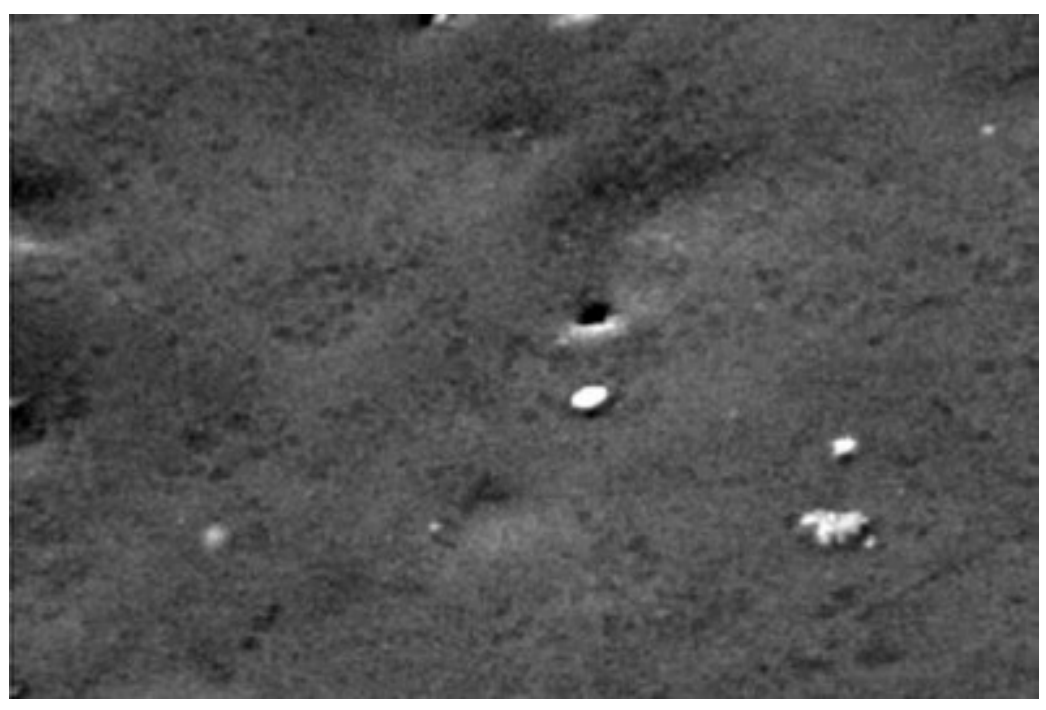

2. Microwave-glazed IPS d.Sign porcelain (×1000 magnification).

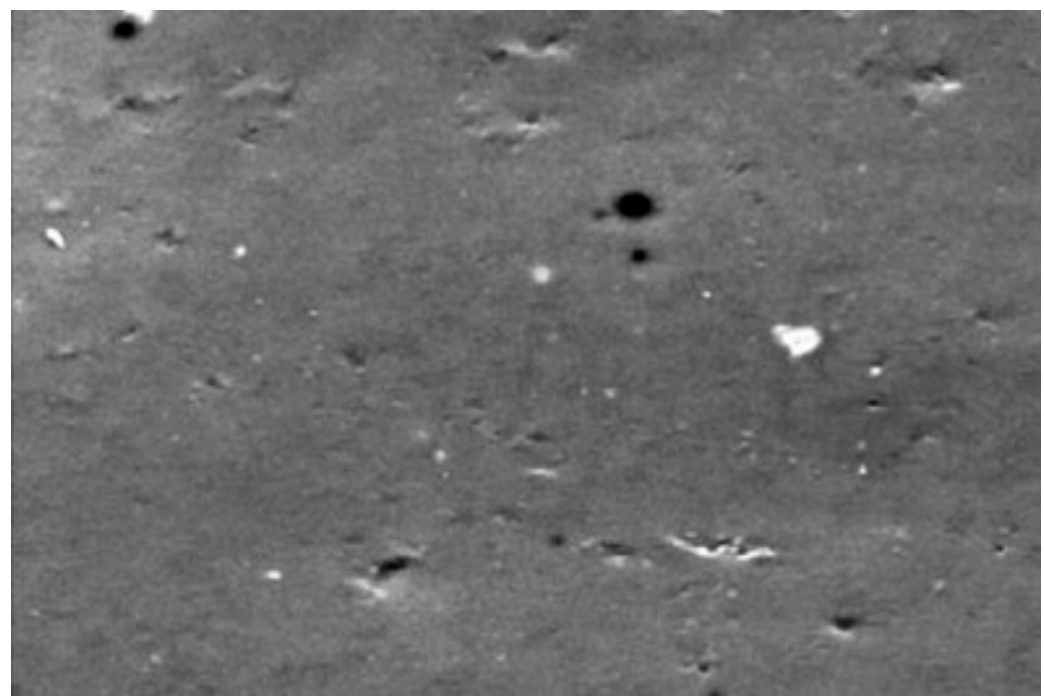

3. Microwave-glazed Omega 900 porcelain (×1000 magnification). 


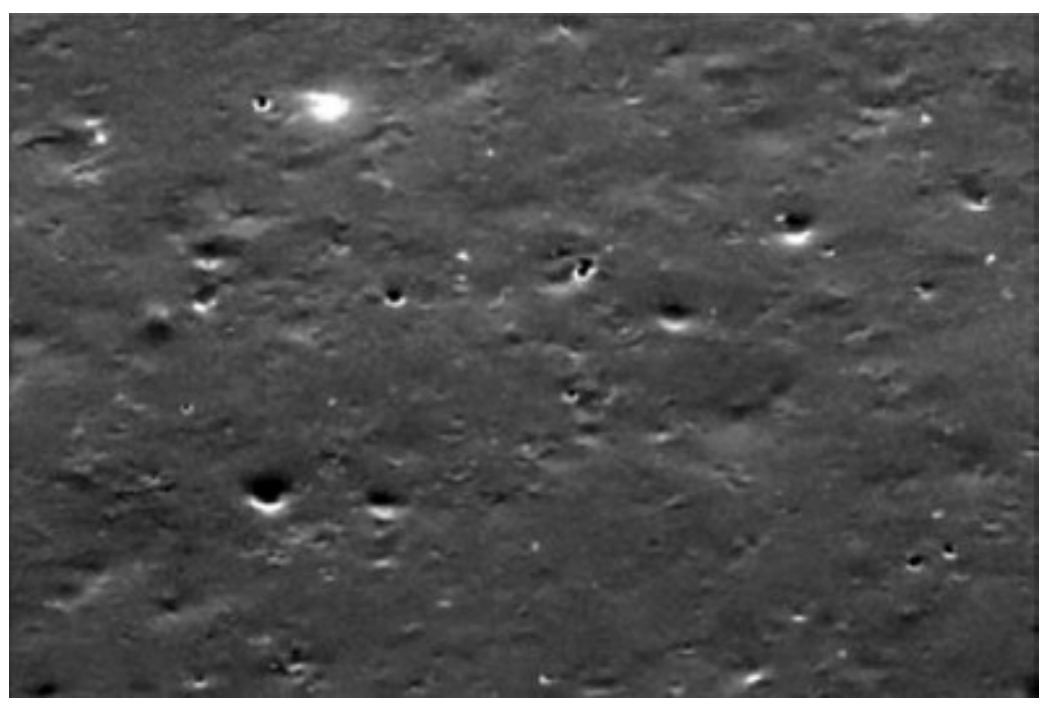

4. Oven-glazed IPS d.Sign porcelain (×1000 magnification).

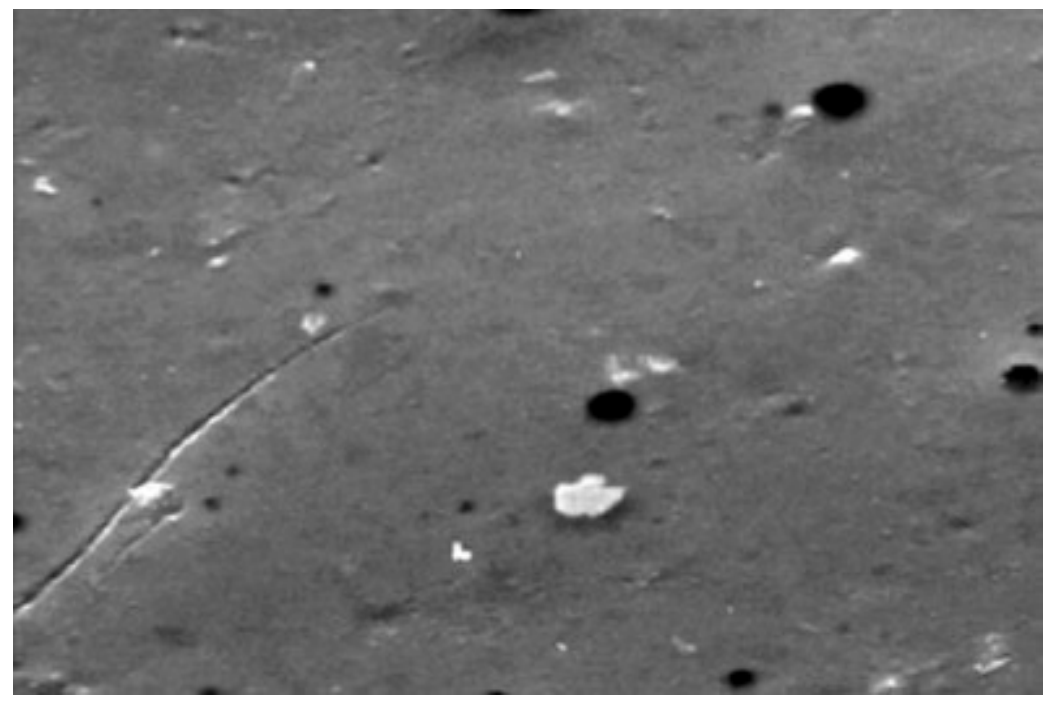

5. Oven-glazed Omega 900 porcelain ( $\times 1000$ magnification). 


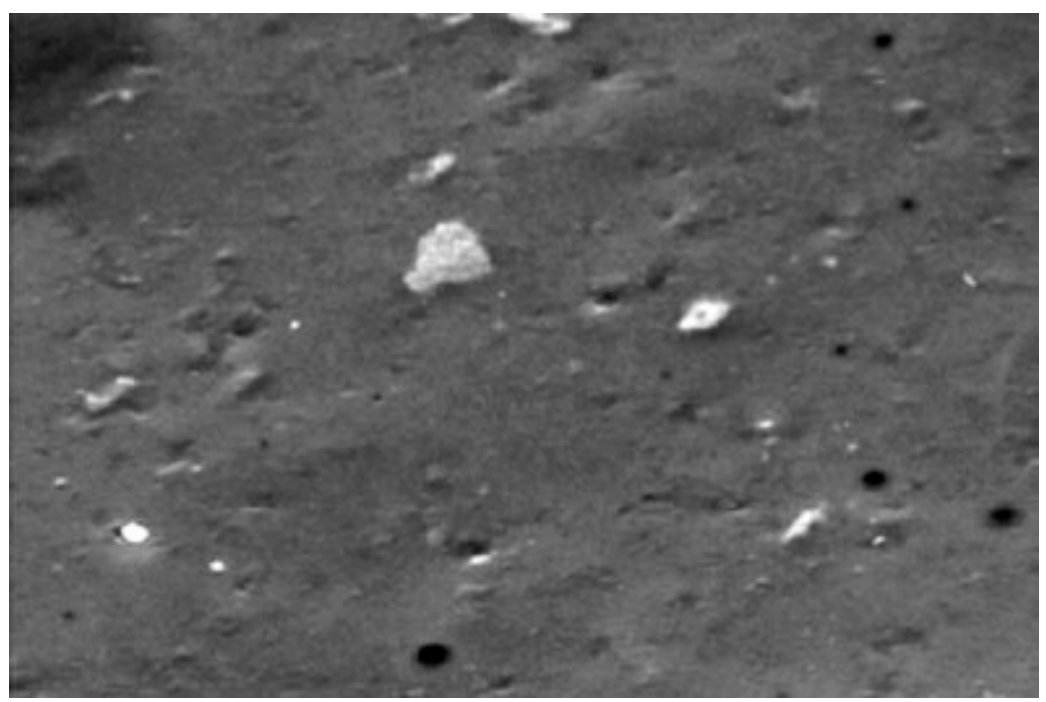

6. Omega 900 porcelain ( $\times 1000$ magnification).

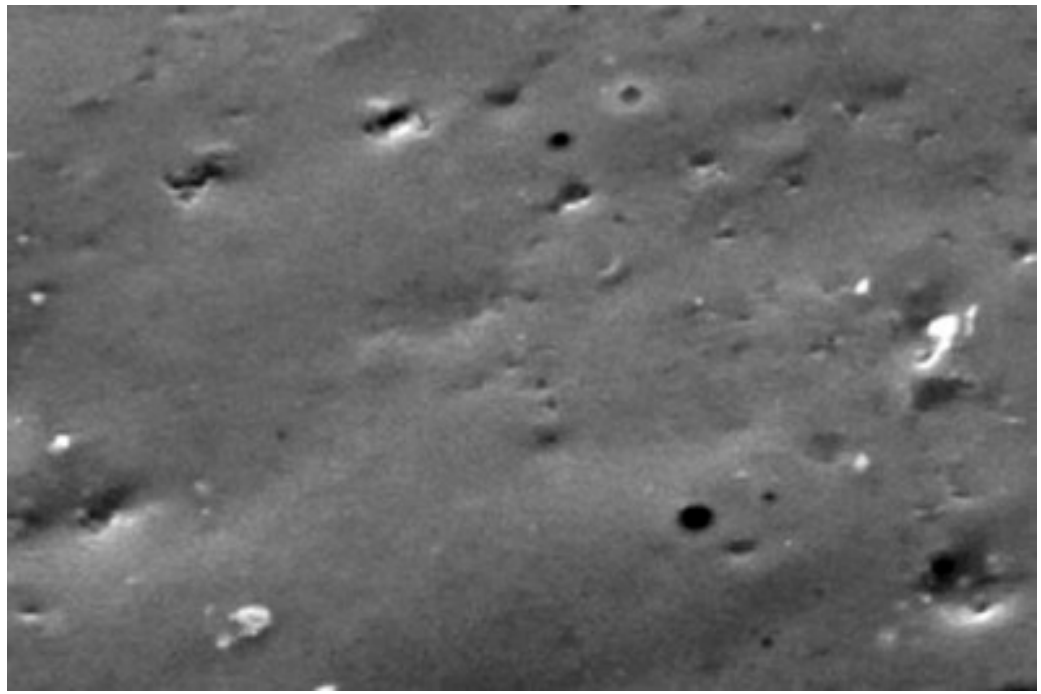

7. IPS d. Sign porcelain (×1000 magnification).

\section{Discussion}

The null hypotheses that there would be no difference between the surface roughness and flexural strength among the 3 treatment groups for the 2 types of porcelain were rejected. The surface roughness was found to be dependent on the surface treatment of the ceramic specimen. There was a significant difference observed between microwave-glazed specimens and conventional oven-glazed specimens. Microwave-glazed porcelain had lower surface roughness than conventional oven-glazed porcelain. This may be attributed to the fact that microwave sintering resulted in a reduced number of porosities. 
All 3 surfaces (hand polished, oven glazed, and microwave glazed) appeared clinically acceptable based on visual examination. However, when viewed under the scanning electron microscope, the handpolished specimens showed greater surface irregularities than the oven- and microwave-glazed specimens. When these surfaces were scanned with a contact profilometer, the small irregularities on the surfaces of hand-polished specimens were only minimally detected. This could be explained by the fact that $\times 100$ and $\times 1000$ magnifications were used to view specimens under the scanning electron microscope, whereas the magnification of the profilometer was between $\times 35$ and $\times 100$. The number and size of voids appeared to be greater in oven-glazed specimens than in hand-polished and microwave-glazed specimens under the SEM. These surface voids were large enough to be detected by the profilometer stylus. In microwave-glazed specimens, when voids were present, they appeared to be fewer in number and smaller in size. This may be explained by the fact that microwaves achieve uniform sintering, resulting in greater densification and reduced surface porosities and irregularities. Therefore, although the SEM images of microwave-glazed and oven-glazed specimens appeared similar, the presence of large detectable surface voids gave oven-glazed specimens a rougher reading on the profilometer scanning.

Data obtained from the 3-point bend test demonstrated that Omega 900 specimens had a higher flexural strength than the IPS d.Sign specimens. One of the variabilities of flexural strength is related to flaw size distribution and can be appraised through the Weibull modulus. The application of Weibull statistics can be made only if certain requirements are fulfilled. The most important of these requirements are the brittleness of the material and the assumption that the strength is controlled by the presence of critical flaws. Implicit in the weakest link model is that failure is due to sudden catastrophic growth of preexisting flaws. Each flaw corresponds to a certain local failure stress. Failure at the most serious flaw (that is, the flaw with the lowest fracture stress) results in immediate failure of the entire specimen.

The Weibull modulus values for Omega 900 microwave-glazed specimens demonstrated higher values (1.9) compared to the other groups of specimens. The higher values for Omega 900 microwave-glazed specimens indicated less variation in strength and a similar distribution of flaws among the specimens. The Weibull modulus value of Omega 900 oven-glazed specimens was slightly lower (1.7) than Omega 900 microwave-glazed specimens. The $m$ values for the 3 groups of IPS d.Sign porcelain were lower than that of Omega 900 porcelain. Overall, IPS d.Sign showed greater voids and porosities when compared to Omega 900 porcelein. Apart from the presence of porosities, the reduced flexural strength of IPS d.Sign porcelain could also be due to its inherent structural characteristics.

Findings of the present study supported the results obtained by Morgano et al $\underline{13}$ on the strengthening effects of glazing on ceramics. The current study did not show any significant differences in flexural strength among different surface treatments, namely, hand polished, microwave glazed, and oven glazed. However, a significant difference in flexural strength was observed for Omega 900 porcelain as compared to IPS d.Sign porcelain.

Glazing of some porcelains in a conventional oven includes a vacuum phase. The absence of the vacuum phase in microwave glazing could be a limitation of the study. It is difficult to achieve vacuum in a microwave chamber due to the risk of generating sparks. One method to overcome this limitation 
may be to perform glazing under pressure in a microwave. Future investigations of microwave glazing under pressure could prove to be promising. This study only focused on the effect of microwave glazing on 2 commonly used dental porcelains; namely, IPS d.Sign and Omega 900. The effect of microwave glazing on other porcelains could be different. Another limitation is that the mean dimensions of all the specimens prior to finishing and hand polishing were not measured. There could have been slight dimensional differences among the specimens at the outset, which were not accounted for in the study. Also, the surface roughness of all of the specimens was not measured before the surface treatments. Therefore, it is not known whether the specimens were rougher or smoother at the start and that the difference observed after the treatments was truly due to the difference in conventional oven-glazing and microwave-glazing techniques.

\section{Conclusions}

Within the limitations of this study, the following conclusions were drawn:

1. The surface character of microwave-glazed porcelain was superior to oven-glazed porcelain. Polishing alone, without glazing, was comparable to glazing with a microwave or a conventional oven.

2. The flexural strength results showed that, irrespective of the manner in which the specimens were treated, Omega 900 porcelain specimens had a significantly higher flexural strength than the IPS d.Sign porcelain specimens.

3. Weibull modulus values indicated that flexural strength performance for Omega 900 microwaveglazed specimens was superior to the other groups of specimens. Microwave glazing may be a viable option for glazing porcelain specimens.

4. The surface of microwave-glazed porcelain had fewer voids and appeared to be smoother when compared to the conventional oven-glazed specimens. Omega 900 specimens appeared to have fewer voids and surface irregularities when compared to IPS d.Sign specimens.

\section{Acknowledgements}

The authors thank the following for valuable contributions to this paper: Mr Peter Bush for help with profilometer scanning and SEM sections, and Mr Robert Dunford, Dr Sandeep Menon, Dr Patrick Hardigan, and Dr Sibel Antenson for assistance with Weibull statistics.

\section{References}

${ }^{1}$ The glossary of prosthodontic terms, J Prosthet Dent, 94 (2005), p. 57

${ }^{2}$ KJ Anusavice, Phillips' science of dental materials (11th ed.), Elsevier, St. Louis (2003), p. 672

${ }^{3}$ GE Monasky, DF Taylor Studies on the wear of porcelain, enamel and gold, J Prosthet Dent, 25 (1971), pp. 299-306

${ }^{4} \mathrm{~N}$ Barghi, L Alexander, RA Draugh When to glaze-an electron microscope study, J Prosthet Dent, 35 (1976), pp. 648-653 
${ }^{5}$ DA Newitter, ER Schlissel, MS Wolff An evaluation of adjustment and postadjustment finishing techniques on the surface of porcelain bonded-to-metal crowns, J Prosthet Dent, 43 (1982), pp. 388-395

${ }^{6} \mathrm{ML}$ Swartz, RW Phillips Comparison of bacterial accumulations on rough and smooth enamel surfaces, J Periodontol, 28 (1957), pp. 304-307

7 JA Clayton, E Green Roughness of pontic materials and dental plaque, J Prosthet Dent, 23 (1970), pp. 407-411

${ }^{8}$ SF Rosenstiel, MA Baiker, WM Johnston Comparison of glazed and polished dental porcelain, Int J Prosthodont, 2 (1989), pp. 524-529

${ }^{9} \mathrm{R}$ Giordano, M Cima, R Pober Effect of surface finish on the flexural strength of feldspathic and aluminous dental ceramics, Int J Prosthodont, 8 (1995), pp. 311-319

${ }^{10} \mathrm{~N}$ de Jager, AJ Feilzer, CL Davidson The influence of surface roughness on porcelain strength, Dent Mater, 16 (2000), pp. 381-388

${ }^{11}$ KC Cheung, BW Darvell Sintering of dental porcelain: effect of time and temperature on appearance and porosity, Dental Mater, 18 (2002), pp. 163-173

${ }^{12} \mathrm{M}$ Baharav, BZ Laufer, R Pilo, HS Cardash Effect of glaze thickness on the fracture toughness and hardness of alumina-reinforced porcelain, J Prosthet Dent, 81 (1999), pp. 515-519

${ }^{13} \mathrm{R}$ Ahmad, SM Morgano, BM Wu, RA Giordano An evaluation of the effects of handpiece speed, abrasive characteristics, and polishing load on the flexural strength of polished ceramics, $J$ Prosthet Dent, 94 (2005), pp. 421-429

${ }^{14}$ CW Fairhurst, PE Lockwood, RD Ringle, WO Thompson The effect of glaze on porcelain strength, Dent Mater, 8 (1992), pp. 203-207

15 JR Kelly, R Giordano, R Pober, MJ Cima Fracture surface analysis of dental ceramics: clinically failed restorations, Int J Prosthodont, 3 (1990), pp. 430-440

${ }^{16}$ JD Katz Microwave sintering of ceramics, Annu Rev Mater Sci, 22 (1992), pp. 153-170

${ }^{17}$ WR Tinga, WA Voss, Microwave power engineering, Academic Press, New York (1968), pp. 189-199

${ }_{18} \mathrm{JH}$ Booske, RF Cooper, SA Freeman Microwave enhanced reaction kinetics in ceramics, Mat Res Innovat, 1 (1997), pp. 77-84

${ }^{19}$ R Roy, D Agrawal, J Cheng, S Gedevanishvili Full sintering of powdered-metal bodies in a microwave field, Nature, 399 (1999), pp. 668-670

${ }^{20} \mathrm{AJ}$ Berteaud, JC Badot High-temperature microwave heating in refractory materials, J Microwave Power, 11 (1976), pp. 315-320

${ }^{21}$ WH Sutton Microwave processing of ceramic materials, Am Ceram Soc Bull, 68 (1989), pp. 376-386

${ }^{22}$ WD Kingery, HK Bowen, DR Uhlmann, Introduction to ceramics (2nd ed.), John Wiley \& Sons, New York (1976), pp. 930-937

${ }^{23}$ MP Harmer, RJ Brook Fast firing-microstructural benefits, J Br Ceram Soc, 80 (1981), pp. 147-148

${ }^{24}$ Council on Dental Materials, Instruments and Equipment. ANSI/ADA specification no 69- Dental ceramic, American Dental Association, Chicago (1991)

${ }^{25}$ LA Rinn, The polychromatic layering technique: a practical manual for ceramics and acrylic resins, Quintessence, Chicago (1990), pp. 54-56 
26 M Guazzato, M Albakry, SP Ringer, MV Swain Strength, fracture toughness and microstructure of a selection of all-ceramic materials. Part I. Pressable and alumina glass-infiltrated ceramics, Dent Mater, 20 (2004), pp. 441-448 